\title{
Espacios de fe. Resignificación religiosa en Nigeria contemporánea
}

María Eugenia Arduino ${ }^{1}$

Universidad Nacional de Buenos Aires

Universidad Nacional de Luján

Artículo Científico. Material autorizado para su publicación en el Journal de Ciencias Sociales, Facultad de Ciencias Sociales, Universidad de Palermo ${ }^{2}$.

Recibido: $29-7-2015$

Aceptado: 16-10-2015

\section{Resumen}

La difusión de expresiones religiosas derivadas del Cristianismo Protestante y la significativa adhesión a ellas por amplios sectores de población nigeriana contemporánea constituyó un devenir en el que intervinieron factores diversos, tales como fragmentación social, necesidades económicas y búsqueda de reivindicaciones políticas, entre otros, en el marco de complejos procesos institucionales locales.

A partir de dicho escenario, la investigación explora aspectos específicos de la apropiación selectiva de religiosidad entre fieles que progresivamente se unieron al Pentecostalismo en áreas urbanas del sudeste del país, a los efectos de interpretar la modalidad de adscripción a dicha fe y de explicar los mecanismos de reelaboración mística producidos a partir de la diversidad etno-cultural vigente.

Metodológicamente, se trabajó con un criterio hipotético-deductivo aplicado a la bibliografía y a las fuentes, complementado por la realización de entrevistas aleatorias flexibles entre los asistentes y colaboradores para comprender el modo en que los fieles autoperciben su identidad religiosa en el marco del proceso de translocalización de ideas y prácticas adaptadas a un ámbito de histórica diversidad religiosa.

La fe Pentecostal, resignificada, habría estimulado a la población del sudeste de Nigeria hacia una transformación simbólica en relación con el cuestionamiento de las religiones heredadas, hacia la apertura a

\footnotetext{
${ }^{1}$ María Eugenia Arduino es Magíster y Especialista en Ciencias Sociales, UNLu, y realizó el Doctorado (Área Historia) UBA. Docente - Investigadora UBA y UNLu. Evaluadora, formadora de recursos humanos y autora de libros y publicaciones científicas. Líneas de investigación: reterritorialización religioso / espiritual afroasiática y relaciones entre política y religión, principalmente en India y Sudáfrica. Mail: arduinoeugenia@gmail.com

${ }^{2}$ El presente artículo es resultado de una investigación desarrollada en el marco de un Proyecto de la Secretaría de Investigaciones, División Investigación, Posgrado y Transferencia del Departamento de Ciencias Sociales de la Universidad Nacional de Luján. Disposición CD-CS: 212-14. Un avance del mismo fue presentado en el Primer Encuentro de Investigadores del Protestantismo Histórico. Buenos Aires, Instituto de Historia Argentina y Americana "Dr. Emilio Ravignani", FF y L, Universidad de Buenos Aires. 23 de abril de 2015.
} 
nuevos contenidos místicos que brindarían inclusión e identidad a los individuos, y hacia un proceso de recomposición socioétnica con el que se sustentaría la estabilidad emocional y el deseo de inserción política.

Palabras clave: Pentecostalismo, translocalización, religiosidad, Nigeria, identidad.

\section{Abstract}

The spread of religious expressions derived from Protestant Christianity and the meaningful adherence to them by large sectors of contemporary Nigerian population constituted a becoming where several factors such as social fragmentation, economic needs and political demands seeking -principally- were involved in the framework of complex local institutional processes.

From this scenario, the research explores specific aspects of selective appropriation of religiosity among faithfuls that gradually ascribed to Pentecostalism in urban areas of the southeast of Nigeria, in order to interpret the mode of attachment to that faith, and to explain the mechanisms of mystical reworking produced from the current ethno-cultural diversity.

Methodologically, we worked with a hypothetical-deductive approach applied to bibliography and sources, complemented by the realization of flexible random interviews among participants and partners so as to understand how faithfuls perceive themselves their religious identity in the context of the translocation ideas and practices adapted to an environment of historic religious diversity.

The Pentecostal faith, resignified, would have stimulated the people of southeastern Nigeria towards a symbolic transformation in relation with the questioning of inherited religions, towards openness to new mystical contents that would provide individuals identity and inclusion; and towards a process of socioethnic recomposition that would sustain the emotional stability and the desire for political integration.

Keywords: Pentecostalism, translocalization, religiosity, Nigeria, identity

\section{Introducción:}

El mundo actual disfruta de más libertad y educación que en ningún otro momento de la historia y, en ese marco, nuevos tipos de espiritualidad han resultado ser aptos para reelaborar, a través de procesos dinámicos, cosmovisiones que sintetizan ideas y prácticas que incluyen valores del pasado junto con elementos actualizados.

La secularización, por su parte, que había sido prevista por los académicos europeos como una manifestación de la modernidad, resultó no tener la incidencia esperada. Así, en el siglo XXI, se asiste a una 
creciente variedad de movimientos de renovación, entre los que la fe Pentecostal alcanza un espacio destacado.

África no fue la excepción en tal proceso, y en ella, dicha creencia, con sus componentes mesiánicos y contestatarios, incursionó lenta pero sostenidamente desde principios del siglo XX. La multiplicación de iglesias y de pastores, unida a singulares discursos locales garantizó su exitosa presencia en numerosas comunidades.

En el caso de la nigeriana, recurrentes situaciones históricas de desorden político -institucional y de deterioro socioeconómico facilitaron la percepción de la necesidad de una reconstrucción posconflicto por medio de una espiritualidad que postulara un nuevo tránsito hacia lo trascendente, de modo inclusivo y contextual.

El presente trabajo propone, por medio de un recorrido histórico y relacional, describir el surgimiento y la difusión de la fe Pentecostal en regiones urbanas del sur de Nigeria contemporánea en las cuales se habrían producido procesos de fusión y pragmática convivencia entre diferentes expresiones místicas.

Aquéllas habrían propiciado en los nuevos fieles una transformación simbólica tendiente a la recomposición socioétnica local dentro de un diversificado espacio cultural, en el que se sustentarían renovadas instancias de estabilidad e inserción tanto económica como política.

La pertinencia de esta temática, en el marco de la intensificación de estudios multiculturales y sobre áreas extraeuropeas, se ubica en relación con la construcción de conocimiento sobre el cual son escasos los trabajos éditos sistematizados que particularicen en el caso nigeriano.

La situación problemática se comenzó a construir a partir de la detección del rápido incremento de adhesión a esa forma de religiosidad, redimensionada desde mediados del siglo XX, divulgada por los mass media $\mathrm{y}$ adoptada por parte de la población local, con características diferenciales y como producto de sucesivas adaptaciones.

Para avanzar en su comprensión, se describió el contexto sociocultural, las posibles causas y el modo a través del cual se produjo una significativa y constante adhesión de un sector de nigerianos a movimientos religiosos particulares desde principios del siglo XX hasta el presente en áreas específicas de dicho país.

El recorte temporal respondió a la delimitación del tópico en un lapso para el cual el fenómeno comenzó, se desarrolló y continuó su profundización hasta el presente. En cuanto al contexto espacial, por su espontaneidad y dinamismo, fue circunscripto a áreas urbanas y suburbanas del sur de Nigeria.

Entre los interrogantes formulados constan los siguientes: ¿qué características socioculturales fueron necesarias para la adhesión al Cristianismo Protestante Pentecostal en Nigeria?; ¿se produjo una fusión o 
una pragmática convivencia entre las diferentes expresiones místicas?; ¿qué impacto ocasionó la práctica de tal religiosidad en la sociedad?

Para responderlos, los objetivos formulados fueron explorar las creencias religiosas de tipo Protestante Pentecostal difundidas en regiones urbanas del sur de Nigeria desde mediados del siglo XX hasta el presente, y describir las causas por las cuales se expandió dicha forma de religiosidad, el modo en que se integró al medio local, la particular expresión que adoptó y la manera por la que continúa su propagación en el presente.

La hipótesis sustentada propone que la expansión del Pentecostalismo habría estimulado a la población local hacia una transformación simbólica particularmente expresada en la ampliación del universo religioso de las comunidades nigerianas; hacia una apertura a otras creencias que habrían brindado espacio y seguridad a los individuos; y hacia un proceso de recomposición socioétnica con la que se sustentaría la inserción socioeconómica.

A su vez, como consecuencia de dicho cambio, la adhesión a las renovadas expresiones de fe podría haber condicionado la activación de sectores sociales urbanos en aspectos relacionados con la participación política y la lucha por el logro de reivindicaciones en el campo sociocultural.

Desde el punto de vista metodológico, se procedió a relevar bibliografía para su examen hipotético deductivo, y luego se la integró a los testimonios obtenidos de unidades informantes relacionadas con los servicios religiosos y los fieles, a los efectos de llegar al enunciado de conclusiones descriptivas.

En síntesis, el presente es un trabajo de tipo interpretativo e interés exploratorio, sobre la base del objetivo de construir conocimientos descriptivos de la adhesión a expresiones de religiosidad Protestante Pentecostal en áreas urbanas del sur de Nigeria en el período indicado.

\section{Fe en expansión}

Desde diferentes miradas conceptuales se ha descripto de modo muy diverso la expansión mundial del Pentecostalismo. En algunos casos, su recepción e inserción fue vista como resultado de la anomia presente entre migrantes y / o poblaciones relocalizadas, y en otros, como una huelga social contra una institucionalidad injusta (Rivière, 1997).

También fue identificada como un nuevo formato místico amenazante de religiosidades históricas, y como la manifestación de utopías locales fundadas en creencias proféticas y milenaristas funcionales al sostén de activos procesos de resistencia étnica que, en ocasiones, se configuraban como movimientos sociales (Gouvêa Mendonça, 2008). 
Distintos teóricos, por su parte, han postulado la explicación de una expansión Pentecostal como producto de su inherente multidiscursividad, la cual conduciría a la reconfiguración de la mismidad como un proceso de dignificación tendiente al logro de la inserción social (Burity, 1997, Saliba, 2003, Ojo, 2004).

En el mismo sentido, aquella también tendería al reforzamiento de la identidad étnica, hecho que potenciaría la movilización de sectores sociales bajos en una sociedad clasista y multiétnica. Finalmente, hubo autores que realizaron una percepción del nuevo movimiento religioso en términos de una contralectura de dominación.

En líneas generales, entonces, la mayoría de los trabajos publicados sobre el tema pueden ser agrupados diferencialmente entre los que realizan un enfoque histórico - estructural - cultural; quienes desarrollan uno económico - político, y aquellos que profundizan el tema desde una perspectiva ontológica.

En el primero, fue valorado el interjuego de factores culturales preexistentes y circunstancias externas que habrían llevado a la emergencia de movimientos sociorreligiosos (Damen, 1996; Riviére, 1997; Willaime, 2006), y en el segundo, se priorizaron factores estructurales para explicar el surgimiento de los movimientos sociorreligiosos urbanos (Codina, 2005; Gouvêa Mendonça, 2002).

En el tercero, se tendió a explicitar la constitución ontológica del mundo nativo, partiendo de las categorías de los actores en relación con las nuevas prácticas místicas (Bastian, 1997; Idoyaga Molina, 1994). Fuera de la anterior agrupación, parte de la bibliografía reciente buscó las causas del rápido y numérico incremento del Pentecostalismo (Míguez, 1983; Sanchis, 1996; Burity, 1994).

Otros autores indagaron sobre variantes poco tratadas y brindaron un panorama de las transformaciones $y$ continuidades de la religiosidad contemporánea, poniendo énfasis en la aparición de neosincretismos y neofundamentalismos (Pace, 2006; Ukah, 2004). Desde una perspectiva sociológica, se incursionó en la teoría de la conversión, incluyendo la controvertida idea del lavado de cerebro (Saliba, 2003).

Así entonces, a partir de mediados de la década de 1920 tanto el surgimiento de nuevas religiones como etapas consecutivas de expansión de otras ya establecidas hacia diferentes áreas geográficas, incluyó al Pentecostalismo, que concretó su propagación desde Estados Unidos hacia Sudamérica y ciudades de Europa y África.

Para explicarla se partió de la idea de que no había similitudes religiosas en África ${ }^{3}$ como para que aquél se difundiera e instalara rápidamente, y que tal fenómeno se produjo propiciado como una derivación colateral de las experiencias fallidas de gobiernos democráticos (Preston, 2001).

\footnotetext{
${ }^{3}$ La presencia de misioneros cristianos tanto protestantes como católicos fue temprana en África, y en el siglo XIX, los respectivos dominios coloniales europeos en dicho continente también propiciaron la llegada de denominaciones diversas como la reformada, la metodista, la anglicana, etc. No obstante, el Pentecostalismo ingresó desde el último tercio del siglo XX, con un discurso diferenciado y cercano a la religiosidad local.
} 
También hubo descripciones del Pentecostalismo como el movimiento religioso contemporáneo de más rápida expansión, unido a cuestiones teológicas que favorecieron la formación de una espiritualidad característica por su modo de relacionarse con los diferentes pueblos y sus culturas (Anderson, 2004).

Para el caso nigeriano, resultó esclarecedor el aporte etnográfico que reconstruyó algunas religiones locales y las interrelacionó con las expresiones transformadas en Nigeria actual, demostrando cómo distintas prácticas y signos lograron ser reconfigurados en el proceso de cambio social (Matory, 2005).

Por lo antedicho, y dado que como todas las religiones el Cristianismo Pentecostal proporcionó senderos hacia lo trascendente, pudo constituir una importante fuente de sanación y reconciliación para un pueblo que, como el nigeriano, obtuvo con su intermediación un modo de hacer las paces con su pasado (Geschiere, 2000).

El fervor religioso que despertó ha generado controversias, ya que ampliaba el papel asignado tradicionalmente a la religión en la sociedad local, y sus áreas de incursión invadieron ámbitos de la privacidad de modo tal que comenzaron a actuar hasta como grupos terapéuticos, de contención social y de orientación política.

Dado que su objetivo último era transformar a la sociedad, quebraron el presupuesto de mantener bajos niveles de tensión social con otros sectores, sobre todo a través de la provocación producida por las intensas campañas de proselitismo, reclutamiento y conversión.

Así, el Pentecostalismo constituyó un conjunto de ejercicios de piedad comunitaria en el que el Espíritu Santo habría creado un clima apto para el trance y la espiritualidad, sosteniendo ideas de milenarismo, mesianismo, conversión, congregacionalismo, de bautismo en el Espíritu Santo y de individualismo.

En cuanto a los contenidos y al discurso que caracterizó a sus enseñanzas, fue notable la reelaboración de las mismas en el marco de la cosmovisión local, en la que se aprehendió la nueva adscripción a través de estructuras de significación, símbolos y modos de categorizar autóctonos (Kivuitu, 2005).

Tal apropiación religiosa fue selectiva, dado que cada practicante pudo procesar los valores que le fueron transmitidos en función de las necesidades emocionales y espirituales que lo llevaron a una reconfiguración de 'la palabra de Dios' propia, como fuente para el triunfo sobre los infortunios de la vida terrenal.

La espiritualidad resultó enriquecida por la incorporación de contenidos como el don de profecías, el bautismo, la facultad de hablar en lenguas o glosolalia, la sanación, entre otros. Los temas bíblicos, apocalípticos y proféticos actuaron reforzando las creencias y como modelo conductual.

Las ventajas de la conversión, considerada un renacimiento, fueron múltiples para aquellos que, provenientes de experiencias de estigmatización, marginalidad, etc., lograrían una reconfiguración de la mismidad, 'ahora soy alguien', 'ahora soy querido', como medio de dignificación tendiente al logro de la 
inserción social, 'ahora pertenezco a la iglesia', 'ahora tengo trabajo', o bien, a la redefinición de la identidad cultural, 'soy Pentecostal', que al ser reafirmada integró a sectores sociales postergados como grupo en una sociedad clasista y multicultural.

Así, el Pentecostalismo, con sus ingredientes mesiánicos y contestatarios, supuso una estrategia de adaptación a una sociedad en crisis; recompuso a la vez el orden tradicional y la presión deculturante global; redefinió la identidad mediante un nuevo culto como el cristiano que, en sus manifestaciones simbólicas, se reencontraba con la religiosidad histórica; constituyó un punto intermedio como forma dinámica de fusión y a la vez colaboró con su flexibilidad dogmática a toda estrategia de adaptación (Anderson, 2001).

La multiplicación de iglesias y pastores, la singularidad local del discurso y un permanente clima de exaltación optimista garantizó su expansión en la sociedad nigeriana, condicionada al escepticismo por sus circunstancias sociopolíticas. La orientación de los contenidos pastorales tendíó hacia un predominio de resolución de aspectos estructuralmente sociales, como la integración, la educación y la inserción política. Por otro lado, la rapidez y el alcance de la expansión pudieron ser explicados como una consecuencia de la multidiscursividad expuesta a través de estrategias comunicacionales. El uso de todos los recursos provistos por los mass media vehiculizó hacia múltiples sitios distantes el mensaje religioso, captando y reteniendo fieles a lo largo del tiempo y el espacio (Clark, 2007).

Las escisiones y el surgimiento de nuevas confesiones, por su parte, derivaron de cuestiones de dogma: disidencias en la interpretación bíblica, en la modalidad de expresividad en el culto, etc. aunque también predominaron elementos de personalismo, cuando la figura del líder espiritual trascendía el mero objetivo pastoral.

\section{Fe relocalizada}

Las instituciones religiosas son también organizaciones sociales que generan y transmiten conocimiento que, cambiante en el tiempo, refleja valores e ideas del contexto vigente. En la era de los procesos globales, África está protagonizando una rápida mutación religiosa, hecho que llevaría a transformaciones en la naturaleza y en los procesos de la producción de lo que se entiende como conocimiento en todo el continente.

Nigeria, por su parte, sería un laboratorio en el que se podría examinar cómo se están llevando a cabo esos procesos, dado que la religión, sus ideas y prácticas, sobre todo destinadas a combatir situaciones socioeconómicas y políticas adversas, se habría convertido tanto en un producto de consumo local como de exportación (Falola, 2008). 
Durante las tres últimas décadas del siglo $\mathrm{XX}$, hubo un resurgimiento de la conciencia religiosa y una proliferación de grupos y lugares de culto en todas las manifestaciones espirituales del país. A raíz de su popularidad y de su capacidad de interpenetración de aspectos de la vida social, la religión se ha convertido en el 'estado por defecto' del discurso político, económico y social local (Amucheazi, 1992).

El caso del suroccidente urbano de Nigeria ilustró de manera elocuente el escenario de la expansión de esa nueva cultura de Dios y su renovada forma de hacer religión, intensificada y con mayor visibilidad social, dado que contuvo diversas actividades, instituciones, ideas, prácticas, redes y estructuras de los grupos e instituciones religiosas (Ukah, 2002).

Tal instancia se caracterizó además por la pluralidad, la competencia y la lucha por el poder y los recursos, por las redes de lealtades y alianzas dentro de ese campo y por la devoción que dio lugar a nuevas constelaciones de conocimiento y prácticas devenidas en una nueva configuración de las formas de hacer religión.

En ese marco, el 'desorden' que imperaba fue descripto como símbolo y consecuencia de una 'falta de conocimiento adecuado sobre Dios y sobre sus planes para la nación'. De ahí que las nuevas enseñanzas hayan sido elaboradas con una variedad de ingredientes locales y translocales, y diseminadas a través de un amplio abanico de medios electrónicos, mecánicos y de boca en boca (Stout - Buddenbaum, 1996).

La producción de conocimiento entre los creyentes y sus redes de transmisión, circulación y consumo fueron importantes para la autoperpetuación de las instituciones religiosas, y aunque el contenido pudo ser interpretado como el conocimiento sobre Dios, de Dios y de los asuntos divinos, las prácticas sociales y su aplicación mostraron que aquel iba más allá de las fronteras religiosas, económicas y políticas.

En la mayoría de los casos se buscaba resolver o reconciliar las situaciones diversas, como por ejemplo, la lucha de trabajadores frente a los continuos ataques a su forma de ganarse la vida y la aparente impotencia de las organizaciones sindicales para protegerlos (Chossudovsky, 1988).

Así, el renovado interés por la religión expresaba la descomposición de las relaciones políticas y económicas locales, al igual que una creciente inestabilidad social, hechos que obligaban a muchos individuos a buscar una teodicea o una visión religiosa renovada del mundo para poner en orden el universo cotidiano que se expresaba de modo caótico.

La compleja realidad de la segunda mitad del siglo veinte, que impactó fuerte en Nigeria, tanto en el pensamiento como en la forma de vida de millones de personas, reemplazó a la antigua seguridad por una sensación omnipresente de inestabilidad económica, incertidumbre e incluso pánico, al igual que una falta de esperanza en el poder para controlar el entorno y futuro propios (Howell, 2004). 
Ante ello, un nueva 'clase social religiosa', conformada principalmente por pastores y evangélicos con educación universitaria e integrantes de sectores medios urbanos proclamaban haber tenido un llamado divino por el cual su misión era asumir el compromiso con la situación e iniciar la tarea de producir tipos de conocimiento apropiados para imponer control en los procesos sociales, económicos y políticos del presente: algo así como una nueva cultura religiosa para Nigeria (Ojo, 1986).

Los intentos de generar un 'nuevo orden mundial' basado en un 'conocimiento religioso' no estarían limitados a un escenario específico, sino que, siguiendo los patrones de fe, las nuevas tecnologías y los múltiples escenarios, podrían llegar al 'público sediento de espiritualidad' (Comaroff, J., 2009, p. 46).

Así, la multiplicación de ministerios en la nueva economía religiosa de Nigeria ha intensificado en las últimas décadas el papel del conocimiento de Dios y de la retórica que en él subyace. Según argumentaron los nuevos expertos en religión, dicho saber, y no el emanado de la ciencia y tecnología, sería el que resolvería los problemas de la nación, que a su vez, sería la proveedora privilegiada de auxilio divino.

No fue casual que se produjera tal evolución en un país en el cual la religión estuvo históricamente omnipresente tanto en la vida privada como en la pública, en casi todas las ciudades principales del país y particularmente en el sur, donde predominó el cristianismo. Así, la fe y el vínculo con Dios evolucionaron dentro de un contexto de carencia y penuria: la pobreza masiva de la mayoría frente a la sofocante riqueza de unos pocos.

En las calles proliferaron edificios religiosos, afiches propagandísticos, tiendas de artículos relacionados y grupos de difusión, propagandas radiotelevisivas, periódicos, etc. a través de los cuales se detalla la naturaleza de los servicios y mercancías, principalmente relacionados con la salud - sanación, el enriquecimiento y la protección contra el mal, convocando a la asistencia y a la participación ${ }^{4}$.

Entre las formas de revitalización religiosa, el Pentecostalismo cobró auge en las últimas tres décadas del siglo $\mathrm{XX}$, coincidentemente con la postguerra civil, momento decisivo en la reconstrucción de la Nigeria contemporánea en términos políticos, económicos, sociales y religiosos. Algunos predicadores interpretaron la guerra y sus horrores como el castigo a una sociedad decadente, por lo cual, la redimensión de la fe era vital ${ }^{5}$.

La variable económica fue decisiva, dado que el fuerte auge del país como exportador de petróleo generó un clima de euforia y bonanza que se extendió hasta 1983. En esos años, la inversión en educación en todos los niveles, especialmente universitario, fue fuerte, al igual que el contacto con Gran Bretaña y Estados

\footnotetext{
${ }^{4}$ Muchos líderes del Nuevo Pentecostalismo hacían publicidad diciendo que eran consultores financieros que enseñan las 'estrategias del Reino' para alcanzar el camino del éxito. Difundían diarios, revistas, cintas de audio y video, panfletos y libros para aportar 'las más grandes armas para alcanzar el éxito'.

${ }^{5}$ La Guerra Civil Nigeriana se produjo entre el 29 de julio de 1967 (luego de que el Coronel Ojukwu fundara la República de Biafra el 30 de mayo de 1967 ) y el 15 de enero de 1970, tras la rendición oficial del Ejército Separatista de Biafra. El gobierno federal, bajo el mando del General Yakubu Gowon, inició la etapa de las Tres Erres: Reconciliación, Reconstrucción y Remutación.
} 
Unidos. Desde esos países los nigerianos recibieron mucho material que colaboró con la renovación religiosa (Gifford, 2001).

Pero cuando los precios del petróleo colapsaron en 1983, y comenzó una oleada de dictaduras militares que produjo saqueos irracionales de la economía, el panorama cambió: se sucedieron devaluaciones monetarias, medidas restrictivas sobre las importaciones de materia prima para las industrias y fábricas, disminución de los salarios y de puestos de trabajo, altos índices de inflación, violencia y crímenes.

Con ese presente de desorden social, la religión se convirtió en un instrumento apto para su manejo y para la reconstrucción. Desde los sectores ilustrados comenzó a surgir una reacción de 'naciente cristiandad de campus universitario', y lo ocurrido hasta ese momento fue interpretado como 'el fin de los tiempos' previo a la 'iluminación final que estaba por venir'.

La década de 1980 fue así un período de consolidación de esta espiritualidad de nueva generación, y la siguiente, que trajo la intensificación del proceso de decadencia, fue una etapa de expansión ${ }^{6}$. En ese escenario, Dios, a través de líderes carismáticos individuales, se convirtió en la respuesta a los problemas de escasez frente a los cuales se encontraba la sociedad: hambre, enfermedades, inseguridad, pobreza, subdesarrollo, deterioro de la educación, falta de agua y electricidad, etc. (Gaiya, 2002).

Específicamente, el desempleo y la inflación agobiantes fueron afrontados de varias formas: emigración, trabajo informal tanto legal como ilegal, alistamiento en alguna de las distintas milicias étnicas que abundan en el sur de Nigeria, o bien, incorporación a una iglesia de nueva generación que les prometía dinero fácil, ascenso económico y milagros en un día, junto con la posibilidad de convertirse en pastor y / o instituir una iglesia / ministerio por un llamado divino a evangelizar.

\section{Fe resignificada}

En la década de los noventa, una inmensa industria religiosa estructurada sobre nuevas formas de conocer, creer y pertenecer proliferó en el sur de Nigeria, con el objetivo de llevar a cabo el mandato divino de rescatar un estado decadente, iniciar una regeneración moral y traer auxilio económico a una sociedad civil perdida y frustrada en los dolores y dificultades de un cambio. Así, el país produjo su versión del cristianismo a partir de su propia historia y experiencias sociales (Falola, 2005).

La Redeemed Christian Church of God, por ejemplo, prometía riquezas, salud y prosperidad asegurada por Dios desde una nueva perspectiva que hizo énfasis en la realización instantánea del enriquecimiento

\footnotetext{
${ }^{6}$ Los regímenes consecutivos de Muhammed Buhari, Ibrahim Babangida y Sanni Abacha entre 1999 y 2006 , cada uno peor que su antecesor, constituyeron una (des)administración civil y etapa antidemocrática, proceso más doloroso que los regímenes militares de los ochenta y los noventa juntos.
} 
adoptando la práctica de dar bienes o servicios para superarse, recibir y contrarrestar los males socioeconómicos ${ }^{7}$.

Su fundador había sido el reverendo Josiah Olufemi Akindayomi, nacido en 1909 en el actual estado de Ondo, en el sudoeste de Nigeria, donde fue curandero y babalawo (padre de los secretos y conocimientos escondidos), hasta que en 1927 ingresó como miembro de la Church Missionary Society.

En 1940 emigró por 'instrucciones divinas' a Lagos, pasando por lle-Ife, la ciudad sagrada de la comunidad yoruba, donde fue formalmente nombrado predicador y profeta de la Eternal Sacred Order of Cherubim \& Seraphim (The Eternal Sacred Order of Cherubim and Seraphim' s.f.), una de las iglesias Aladura ${ }^{8}$ que surgió a mediados de la década de 1920 (Peel, 1968).

Ya en Lagos, se estableció en un suburbio donde era muy popular por sus conocimientos sobre el futuro y sus dones especiales para sanar y hacer milagros. Ascendió al rango de Apóstol en la jerarquía de la Iglesia y formó un pequeño grupo de seguidores (Schoffeleers, 2000).

Su fama creciente lo animó a convertir a su grupo en una iglesia con el nombre de ljo Ogo Oluwa y en 1952 la redenominó como Redeemed Christian Church of God, nombre que decía haber recibido por revelación divina, al igual que las directivas para darle una nueva identidad Pentecostal. Murió en 1980, momento en el que lideraba 39 templos en Lagos y sus alrededores con unos mil adeptos.

Como sucesor, Josiah había nombrado al profesor universitario doctorado en matemática Enoch Adejare Adeboye, quien había sido miembro de esa iglesia desde hacía siete años y contaba con 39 cuando tomó a su cargo el ministerio en enero de 1981 (Ojo, 2001).

El conjunto de elementos que transmitía la Iglesia con Josiah incluía: desprecio por la modernidad y la riqueza, separación espacial de sexos en el encuentro religioso, momento en el que también se prohibía el uso de instrumentos musicales, de pantalones en las mujeres, del uso de motos y bicicletas, del arreglo del cabello y del uso de adornos faciales artificiales, de desempeñar empleos en manufacturas, distribución y venta de alcohol o tabaco, y en los sectores militares o paramilitares.

La explicación de tales prohibiciones se basaba en que no eran actividades que estuviesen en consonancia con las doctrinas de la iglesia. Los miembros del templo que incurrían en alguna falta eran azotados en público, y los fieles se caracterizaban por llorar mucho en cada oficio religioso de manera tal que la iglesia se hizo conocida entre la gente de los alrededores como la ljo Elekun, 'la iglesia de los que lloran'.

\footnotetext{
${ }^{7}$ Se tomó como ejemplo esta Iglesia debido a su exponencial crecimiento y su presencia actual en más de 100 países del planeta y 15.000 templos en Nigeria. http://www.rccg.org/ Consultado el 7 de julio de 2015

8 Dichas adscripciones se expandieron en Nigeria desde que en 1918, en ljebu-Ode, dos integrantes de la Iglesia Anglicana San Salvador se separaron de ella e iniciaron un movimiento de renovación en busca de la verdadera espiritualidad, que se reforzó cuando ante una epidemia de influenza fue usada la oración o egbe aladura, en procura de salvar vidas. Esta línea Pentecostal se basó en el poder de la oración y en todos los efectos / manifestaciones del bautismo del Espíritu Santo.
} 
Adeboye introdujo grandes modificaciones desde que asumió el liderazgo, que aún hoy mantiene en el ministerio. Nacido en una familia anglicana, 'renació' el 29 de julio de 1973, meses después de comenzar a ir al templo para encontrar la sanación de su hija enferma. Fue un estudiante regular de teología de la prosperidad, y adquirió las capacidades organizacionales para sus encuentros con los tele-evangélicos americanos (The Redeemed Christian Church of God. 63rd Annual Convention Programme. Pastor E. A. Adeboye, s.f.).

Durante sus primeros diez años de tarea pastoral, reposicionó a la iglesia en términos sociales y doctrinales de modo gradual. Tal transformación respondía a un proceso más amplio de cambio dentro mismo de la sociedad nigeriana. Adoptó el ethos de la santidad, propició una nueva doctrina de la prosperidad y estimuló la creencia en el poder de la mente humana para manifestar la fe en Dios y lograr resultados positivos de riqueza y salud. Esas ideas fueron revolucionarias, teniendo en cuenta las antiguas imposiciones, y constituyeron una refundación institucional ${ }^{9}$.

El nuevo paradigma religioso incluyó el permiso para obtener lo mejor del mundo material y la difusión de esa posibilidad con el uso de los medios masivos de comunicación: audiovisuales, satelitales y virtuales. También introdujo una amplia gama de nuevos productos religiosos, como programas de milagros, sanación transcongregacional, y cadenas de oración que atrajeron a miles de devotos.

A través de los años, Adeboye ha ascendido dentro de la esfera pública Pentecostal para convertirse en su más importante empresario religioso, con un fuerte reconocimiento público, al tener acceso a un tipo de conocimiento único, inimitable, que incidía en el comportamiento político y económico en Nigeria.

Para los Pentecostales de ese país, el conocimiento religioso emana de la mente de Dios, quien transmite su infalible palabra en un territorio sagrado como el nigeriano con la misión de cambiar el curso de la vida. La grandeza del país surgiría cuando la nación le proveyera a los otros grupos de personas de la comunidad global el conocimiento divino. En tal sentido, Adeboye realizó profecías públicas cada año con respecto al curso de los acontecimientos de individuos, de la nación y del mundo en general (The Redeemed Christian Church of God. 63rd Annual Convention Programme. Pastor E. A. Adeboye, s.f).

Éstas constituyen lo que él llama el 'conocimiento de las revelaciones', pronunciamientos proféticos hechos desde el púlpito, un lugar donde se concentraría el poder sagrado. Tal conocimiento del famoso pastor con frecuencia ha tenido un papel importante en el ámbito político local, con el cual favorece, por lo general, al

\footnotetext{
9 ....Fuerzas ocultas, lideradas por el Espíritu de la pobreza pueden estar bloqueando tu camino hacia la riqueza. Espíritus seductores, te obligan a despilfarrar tu dinero en cosméticos, perfumes y otras tonterías, mientras que la brujería y los espíritus de los antepasados tienen el poder de impedir que progreses en esta vida. Por eso, la promesa de enriquecimiento que el Evangelio de la Prosperidad contiene, depende de que seas liberado de todos ellos, de que los expulses de tu vida para siempre por medio de un exorcismo para expulsar a todas las fuerzas del mal y permitir la entrada del Espíritu Santo en una sincera conversión. También debes romper con todos los lazos de sangre con la parentela porque representa una carga, constantemente hay que satisfacer peticiones para ritos funerarios, sacrificios a los antepasados, enfermedades de paisanos...' (The Redeemed Christian Church of God. $63^{\text {rd }}$ Annual Convention programme. Organización, s.f.).
} 
partido en el poder ${ }^{10}$. Así, el poder religioso se relaciona con el político, reforzando a cada uno (Freston, 2004).

Según lo antedicho, el conocimiento religioso obtenido conllevó incluso un valor de mercado en tanto que hasta hubo organizaciones multinacionales (Procter \& Gamble, Coca-Cola, Unilever, etc.) que han hecho alianzas con las megaiglesias y comercializaron juntas sus respectivos productos (Visaomda, 2014).

Fuera de las actividades religiosas propiamente dichas, la iglesia ha establecido una estructura compleja para institucionalizar ese conocimiento y transmitirlo a futuras generaciones. Fundó y sostuvo escuelas y guarderías de nivel inicial y medio, de informática, vocacionales, de administración, academias de profesionales, de misioneros, y universidades. Así, a todos los espacios llegó la presencia y producción de la cultura de materiales religiosos (Maxwell, 2000).

La tecnología, por su parte, fue vital para la transmisión de ideas. Imágenes y sonidos, audiovisuales y discos compactos digitales de los sermones y de otras actividades, fueron reproducidos para ser comercializados dentro y fuera del país. Cada una de las más de 7000 ramas de la iglesia en más de cien países constituyó un punto de difusión de tales materiales, complementados por un sitio web, una radio por internet y un canal de televisión satelital (Luhmann, 2000).

Este Nuevo Pentecostalismo de Nigeria, segundo producto de exportación después del petróleo crudo, recluta cada año miles de misioneros que han sido entrenados para llevar la palabra de Dios y el Espíritu Santo al mundo. Miembros laicos, por otro lado, son enviados a las distintas regiones para hacer apostolado y difundir el mensaje de Adeboye (RCCGRTVM, 2013).

En conclusión, Nigeria ha vivido y vive momentos de resignificación religiosa, devenida de un contexto de prolongadas dislocaciones locales. En el marco de ellas, la religión se convirtió en un recurso, entre otros, apto para promover una transformación rápida y reparadora. Así, un nuevo sector religioso, que se adjudica poderes y conocimiento especiales, ha surgido para llevar a las masas hacia una intensificación espiritual que desafía a un estado que ha fallado.

La contribución más importante de este ministerio se puede ver en que el saber religioso ha contribuido con una relativa regeneración social, económica y política. A su vez, las destrezas comunicacionales de la iglesia y sus alianzas económicas han constituido una eficaz estrategia de recuperación que evidencia el impacto social de lo religioso, particularmente en un estado que cada día enfrenta complejas realidades.

\footnotetext{
${ }^{10}$ Entre los partidos políticos que actualmente están en actividad en Nigeria, los que son de base religiosa Pentecostal y que poseen vínculos con el gobierno son: Peoples Redemption Party or PRP, Peoples Salvation Party or PSP, United Nigeria Peoples Party or UNPP, Alliance for Democracy or AD, All Nigeria Peoples' Party or ANPP.
} 


\section{Consideraciones finales}

Las iglesias Pentecostales en Nigeria constituyen un tema de innegable interés para quien se interese por la dinámica de las interacciones sociorreligiosas. Son verdaderos laboratorios donde se expresa la fuerza de los sistemas de pensamiento y de las lógicas tradicionales, la capacidad de resistencia, integración y reinterpretación de los diferentes sectores socio - etno - económicos confrontados a nuevas ideologías y prácticas.

Así, dicho Cristianismo contribuyó, desde la primera década del siglo XX, con su mensaje fuertemente mesiánico, a que los sectores surnigerianos de más bajos recursos, urbanos y suburbanos, resignificaran su espiritualidad. El norte, por su parte, permaneció bajo la tutela musulmana, hecho conflictivo hasta el presente.

Dicha fe, impulsada por una agenda de dolor social junto con la reducción de calidad de la vida, introdujo una nueva forma de practicar la religión, una manera reelaborada de creer y de pertenecer. Sus defensores basan su convicción en un renovado tipo de conocimiento, y la Redeemed Christian Church of God, de Lagos, liderada por el Pastor Enoch A. Abedoye es la principal Iglesia a través de las cuales dicho conocimiento se manifiesta.

En sus ceremonias, los fieles relatan que 'es palpable el calor fraternal, la bienvenida y la participación, y que la iglesia representa una verdadera comunidad'. El sentido de inclusión, pertenencia e identidad es constante y las denominaciones de 'nosotros' y 'hermano' tienen un importante significado en la mayoría de los asistentes.

Esa búsqueda de inclusión es uno de los elementos más importantes en el proceso de la conversión. La solidaridad del grupo se presenta como una oportunidad para desarrollar la propia personalidad al experimentar la plenitud de 'ser alguien'. Se trata de una reacción contra la anomia en la que se estaba viviendo, sentimiento clave para su integración y continuidad como miembro activo de la Iglesia.

La idea de un Dios protector, bondadoso y todopoderoso parece no haber existido en el horizonte mitológico local, y la aceptación de los contenidos del cristianismo se relacionaría también con su contención ante temibles teofanías emanadas del mundo intraétnico. En ese sentido, la amplia difusión de aquél, enfatizando la práctica de la sanación a través de la oración, propiciaría la restauración del equilibrio socioemocional

Luego de haber descripto, tal como se propuso en los objetivos, algunos de los antecedentes historiográficos generales y específicos de la Fe Pentecostal, parte de las interpretaciones explicativas de su constante y amplia expansión durante el siglo XX, los elementos socioculturales que fueron necesarios para su surgimiento y adhesión en el caso nigeriano, resta destacar la importancia de los procesos de fusión y 
pragmática convivencia entre diferentes expresiones místicas, el impacto que produce en la sociedad esta forma de religiosidad, y el fuerte papel que desempeñan los medios masivos de comunicación en la captación y retención de fieles.

Así, resultan confirmadas las hipótesis propuestas para el presente trabajo, afirmándose que la expansión de las renovadas creencias religiosas habría estimulado a la población urbana del sur del actual territorio nigeriano durante el siglo XX hacia una clara transformación simbólica en tres sentidos principales: hacia una ampliación del universo religioso de las comunidades surnigerianas; hacia una apertura a otras creencias que brindaron espacio y seguridad a los individuos; y hacia un proceso de recomposición socioétnica de la propia cosmovisión del mundo, hecho que habría devenido en un nueva expresión espiritual optimista.

Como consecuencia de dicha transformación, la adhesión al Pentecostalismo condicionó la activación de sectores sociales urbanos surnigerianos en aspectos relacionados con la participación política y la lucha por el logro de reivindicaciones en el campo sociocultural. Finalmente, queda destacado el papel de la religión en contextos en los que sus dirigentes pueden guiar procesos de estabilización y recomposición.

\section{Referencias}

AMUCHEAZI, E. (1992). Nigeria, religión y política. En: Ukon, E.U. (Comp) Nigeria contemporánea. Ensayos sobre Sociedad, Política y Economía. Buenos Aires: Edipubli.

ANDERSON, A. (2001). African Reformation: African Initiated Christianity in the 20th Century. Trenton: Africa World Press.

BASTIAN, J. P. (Dir.) (1983). Cristianismo y Sociedad, XXI, 76. Protestantismos y Sociedades Latinoamericanas.

BURITY, J. (1997). Identidade e política no campo religioso: Estudos sobre cultura, pluralismo e o novo ativismo eclesial. Recife: Editora Universitaria UFPE.

CLARK, L. S. (2007). Religion, Media and the marketplace. New Brunswick: Rutgers University Press.

CODINA, V. (1986). Iglesia y Sectas. Aproximación sociológica. En: Fe y pueblo. Boletín ecuménico de reflexión teológica, III, 14, 13-16.

COMAROFF, J. (2009). Violencia y ley en la poscolonia: una reflexión sobre las complicidades Norte - Sur. Buenos Aires: Katz.

DAMEN, F. (1986). El Pentecostalismo: algunos rasgos. En: Fe y pueblo. Boletín ecuménico de reflexión teológica, III, 14, 31-39.

FALOLA, T. \& Heaton, M. (2008). A History of Nigeria. Cambridge: Cambridge University Press. 
GESCHIERE, P. (2000). The Pentecostal Revolution in Nigeria. Copenhagen: University of Copenhagen, Centre of African Studies.

GIFFORD, P. (2001). The Complex Provenance of Some Elements of African Pentecostal Theology. Bloomington: Indiana University Press.

GOUVÊA MENDONÇA, A. (2008). O celeste porvir: a inserção do protestantismo no Brasil. São Paulo:EDUSP. GORE, Ch. \& PRATTEN. D. (2002). Politics of Plunder: The Rhetorics of Order and Disorder in Southern Nigeria. African Affairs, 102, 211-240.

HOWELL, B. (2004). Troubled Journey: Nigeria since Independence. Maryland: University of Press America.

LUHMANN, N. (2007). La realidad de los medios de masas. México, D. F.: Universidad Iberoamericana/Anthropos.

MATORY, L. (1994). Sex and the Empire That Is No More: Gender and the Politics of Metaphor in Oyo Yoruba Religion. Minneapolis: University of Minnesota Press.

OJO, M. A. (2004). "Pentecostalism public accountability and governance in Nigeria". Paper presented for the Pentecostal-Civil Society Dialogue. Lagos, October 18.

OJO, T. (2001). Let Somebody Shout Hallelujah! The Life and Ministry of Pastor Enoch Adejare Adeboye. Lagos: Honeycombs Cards and Prints.

OPOKU, K. A. (1987). La religión en África durante la era colonial. En: Historia General de África. Madrid: Tecnos / UNESCO.

PACE, E. (1997). Credere nel relativo: Persistenze e mutamenti nelle religioni contemporanee. Torino: Utet.

PEEL, J. D. Y. (1968). Aladura: A Religious Movement among the Yoruba. Londres: International African Institute.

PRESTON, P. (2001). Evangelicals and politics in Asia, Africa and Latin América. Cambridge: Cambridge University Press.

RANGER, T. O. (1999). Evangelical Christianity and Democracy in Africa. New York: Oxford University Press. RCCGRTVM (2013). WITH GOD ALL THINGS ARE POSSIBLE by Pastor E. A. Adeboye. https://www.youtube.com/watch?v=x1BOpTUHKIM [video consultado: 19 de julio de 2015].

RIVIERE, Gilles (1997). Bolivie: le pentecôtisme dans la société aymara des hauts - plateaux. En: Problèmes d'Amérique Latine. La diversification du religieux en Amérique Latine. A propos de l'expansion des pentecôtismes. París, Trimestriel № 24, janvier, 81-102.

SALIBA, J. A. (2003). Understanding new religious movements. California: Altamira Press.

SCHOFFELEERS, Matthew. (2000). Religious Encounter and the Making of the Yoruba. Bloomington: Indiana University Press. 
STOUT, D. \& BUDDENBAUM, J. (1996). Religion and Mass Media: Audiences and Adaptations. California: Sage Publications.

The Eternal Sacred Order of Cherubim and Seraphim (s.f.). https://www.facebook.com/pages/The-EternalSacred-Order-of-Cherubim-and-Seraphim/136632929717548 [consulta: 8 de julio de 2015].

The Redeeme Christian Church of God. 63rd Annual Convention programme. Organización (s.f.). https://www.facebook.com/rccg.org?fref=ts [consulta: 21 de junio de 2015].

The Redeeme Christian Church of God. 63rd Annual Convention Programme. Pastor E. A. Adeboye (s.f). https://www.facebook.com/PastorEAAdeboye/timeline [consulta: 20 de junio y el 7 de julio de 2015] UKAH, A. F.K. (2004). Pentecostalism. Religious and expansion and the city. Lessons from the Nigerian Bible Belt. En: Probst, P. \& Spittler, G. (Hrsg.) Resistence and expansion: Explorations of local vitality in Africa (pp. 415-441). Münster: Lit.

VISAOMDA. (2014). Confira o documentario da igreja do Pr. Enoch Adeboye, o líder de uma das maiores igrejas do mundo. https://www.youtube.com/watch?v=6uMZUdFi-r8 [video consultado: 10 de julio de 2015].

WILlAIME, J. P. (1999). Le Pentecôtisme: contours et paradoxes d'un protestantisme émotionel. En: Archives de Sciences Sociales des religions, 44, 105, 5-28. 